\title{
Metabolic syndrome and subclinical carotid atherosclerosis in Mexican children and adolescents with acanthosis nigricans
}

\author{
Cynthia Guadalupe González-Villalobos, ${ }^{1}$ Elizabeth Guevara-Gutiérrez, ${ }^{1}$ Pedro Gutiérrez-Fajardo, ${ }^{2}$ \\ José Alberto Tlacuilo-Parra, ${ }^{3}$ María Elena Sánchez-Castellanos, ${ }^{1}$ Alejandro García-Vargas ${ }^{1}$ and \\ José Fernando Barba-Gómez' \\ ${ }^{1}$ Secretaría de Salud, Instituto Dermatológico de Jalisco "Dr. José Barba Rubio"; ${ }^{2}$ Hospital Bernardette, Echocardiography Laboratory; ${ }^{3}$ nnstituto \\ Mexicano del Seguro Social, Centro Médico Nacional de Occidente, Pediatrics Hospital, Jalisco, Mexico
}

\begin{abstract}
Introduction: Acanthosis nigricans is a marker of insulin resistance that is associated with metabolic and cardiovascular alterations. Objective: To investigate the frequency of metabolic syndrome and subclinical carotid atherosclerosis in children and adolescents with acanthosis nigricans, and to compare the results between genders. Method: Cross-sectional study, where 30 male and 30 female subjects younger than 18 years of age diagnosed with acanthosis nigricans were included. The presence of metabolic syndrome (Cook's criteria), cardiovascular risk (ultrasensitive C-reactive protein and [us-CRP]), and carotid atherosclerosis (intima-media thickness [IMT]) was investigated. Descriptive and inferential statistics was used for data analysis. Results: The frequency of metabolic syndrome was $43 \%$ (males $42 \%$ versus females $58 \%, p=0.58$ ). All patients showed us-CRP abnormal levels: $67 \%$ were classified with moderate cardiovascular risk and $27 \%$ with high risk. The prevalence of carotid atherosclerosis was $98 \%$ (males $49 \%$ versus females $51 \%, p=0.45$ ). Acanthosis nigricans severity did not influence on the results. Conclusions: Intentional search for metabolic syndrome and subclinical carotid atherosclerosis in Mexican children and adolescents with acanthosis nigricans, regardless of gender or disease severity, will enable the implementation of measures to decrease the morbidity and mortality seen in adult age.
\end{abstract}

KEY WORDS: Acanthosis nigricans. Metabolic syndrome. Carotid atherosclerosis. Children. Adolescents.

\section{Introduction}

Acanthosis nigricans (AN) is considered to be a cutaneous manifestation of obesity and insulin resistance. ${ }^{1}$ The latter is the common pathogenic pathway between AN, metabolic syndrome (MS) and atherosclerosis, ${ }^{2}$ given that high serum insulin levels have the following effects:

- They stimulate insulin-like growth factor 1 receptors in dermal keratinocytes and fibroblasts, which favors the development of $\mathrm{AN}^{3}$

- They produce inappropriate lipolysis with an increase in triglycerides and a decrease in high-density lipoprotein (HDL), which facilitate the development of MS. ${ }^{4}$

- They contribute to progressive development of atherogenesis and allow the release of pro-inflammatory cytokines that perpetuate insulin resistance and result in higher endothelial dysfunction..$^{5}$

Given that AN has increased in parallel with obesity increase in the pediatric population ${ }^{3}$ and that, according to the Organization for Economic Cooperation and Development, $29 \%$ of girls and $28 \%$ of boys in Mexico are estimated to experience overweight or obesity, ${ }^{6}$ we would expect a higher presence of metabolic and cardiovascular disorders in this age group, albeit
Correspondence:

José Alberto Tlacuilo-Parra

E-mail: albtlacuilo@yahoo.com
Date of reception: 29-08-2017

Date of acceptance: 08-01-2017

DOI://dx.doi.org/10.24875/GMM.M18000172
Gac Med Mex. 2018;154:389-393

Contents available at PubMed www.gacetamedicademexico.com 
in a search in the literature we did not find data in that regard in Mexican pediatric population with AN. Therefore, our purpose was to investigate the frequency of MS and carotid atherosclerosis in Mexican children and adolescents with $\mathrm{AN}$, and to compare the results between both genders and with those published in the literature.

\section{Method}

Cross-sectional study at Instituto Dermatológico de Jalisco "Dr. José Barba Rubio", after authorization of the Ethics Committee of the institution and signature of consent once the parent or legal guardian of each participant was informed. A convenience sample of 60 patients diagnosed with $\mathrm{AN}$ (30 males and 30 females), Mexicans by birth and with two previous generations of Mexican origin, from 0 to 17 years of age, without prior treatment for AN or other dermatoses associated with obesity, diabetes or lipid disorders was included.

Subjects who in the interview referred having been diagnosed with congenital or acquired disease during the AN evolution, metabolic or lipid alterations or atherosclerosis and those who consumed medications to lose weight, or blood glucose-lowering, antihypertensive or lipid-lowering drugs, growth hormone, sex hormones or glucocorticoids, which are associated with the development of AN. were excluded. Patients with ultrasensitive C-reactive protein (usCRP) values $>10 \mathrm{mg} / \mathrm{L}$ were eliminated, due its association with acute inflammatory processes. ${ }^{7}$

AN diagnosis was clinical and was carried out by a trained dermatologist. Neck involvement and severity having a score $\geq 1$ were considered as conditions for diagnosis. To determine the severity five anatomical sites were taken into account: the neck, axillae, elbows, knuckles and knees. The neck was assessed with regard to extension ( 0 to 4 scale) and severity (texture with a scale from 0 to 3 ). In the axilla, only the extension was assessed (0 to 4 scale). On elbows, knuckles and knees only presence (1 point) or absence ( 0 points) was determined. To define AN severity grades, total evaluation score was classified as absent $(<1)$, mild (1-1.5), moderate (1.6-1.9) and severe $(\geq 2){ }^{8}$

The metabolic syndrome diagnosis was established based on Cook's criteria, ${ }^{9}$ with the presence of 3 or more of the following parameters:

- Waist circumference $\geq 90^{\text {th }}$ percentile for age and gender. With a non-distensible material measuring tape and the patient in the stand-up position, waist circumference was measured from the midpoint between the twelfth rib and the edge of the iliac crest, going through the navel, after a normal exhalation. ${ }^{10}$

- Arterial hypertension $\geq 90^{\text {th }}$ percentile for age, gender and height. ${ }^{9}$ It was taken in a sitting position, with a mercury sphygmomanometer with appropriate cuff for the patient arm length and age, after a 10-minute period of rest. Blood pressure was classified according to normal values for age, gender and height, using the methodology standardized by the Second Task Force. ${ }^{11}$

- Triglycerides $\geq 110 \mathrm{mg} / \mathrm{dL}$. ${ }^{9}$ They were determined using an enzymatic colorimetric method. For their measurement, a peripheral venous blood sample of $10 \mathrm{~mL}$ was obtained after a 12-hour fasting, which also served for the performance of the rest of laboratory tests.

- HDL cholesterol $\leq 40 \mathrm{mg} / \mathrm{dL}^{9}$ and glucose $\geq 110 \mathrm{mg} / \mathrm{dL} .{ }^{9}$ Both were determined by enzymatic colorimetric method.

Atherosclerosis was determined with the carotid intima-media thickness (IMT), defined as the size of the distal wall of the left and right common carotid artery. ${ }^{12}$ It was measured with the patient at rest in the decubitus position, with a longitudinal scan of the right and left common carotid artery being performed with B-mode ultrasound (Philips iE33 Apparatus with L11-3Transducer, ${ }^{\circledR}$ Yorba Linda, CA) along one centimeter. Measurements were made at three points and average value was calculated to obtain the IMT measurement. ${ }^{13-15} \mathrm{Ca}$ rotid IMT $>0.37 \mathrm{~mm}$ was considered abnormal in boys and girls up to 6 years of age, $>0.41 \mathrm{~mm}$ in boys from 6 to 17 years 11 months of age and $>0.39 \mathrm{~mm}$ in girls from 6 to 17 years 11 months of age. ${ }^{16}$

Cardiovascular risk was indirectly determined with usCRP serum levels. ${ }^{17-19}$ A $10 \mathrm{~mL}$ sample of peripheral venous blood obtained after a 12-h fasting was processed by nephelometry. Individuals were defined to have low cardiovascular risk if their levels were $<1 \mathrm{mg} / \mathrm{L}$, with moderate risk if levels were $1-3 \mathrm{mg} / \mathrm{L}$ and with high risk if levels were $>3 \mathrm{mg} / \mathrm{L}$. Patients with levels $>10 \mathrm{mg} / \mathrm{L}$ were excluded, since such levels are associated with acute inflammatory processes. ${ }^{7}$

To compare the proportions, the chi-square test or Fisher's exact test were employed. Student's t-test was used to compare continuous variables with normal distribution. As a measure of association, the odds ratio (OR) with $95 \%$ confidence interval $(\mathrm{Cl})$ was obtained. A $p$-value $<0.05$ was considered to be a statistically significant difference. 
Table 1. Study variables distribution by acanthosis nigricans severity

\begin{tabular}{|c|c|c|c|c|c|c|c|c|}
\hline \multirow[t]{2}{*}{ Component } & \multicolumn{2}{|c|}{ Mild AN $(n=16)$} & \multicolumn{2}{|c|}{ Moderate AN $(n=13)$} & \multicolumn{2}{|c|}{ Severe AN $(n=31)$} & \multirow{2}{*}{\multicolumn{2}{|c|}{$\mathbf{p}^{*}$}} \\
\hline & $\mathrm{n}$ & $\%$ & $\mathrm{n}$ & $\%$ & $\mathrm{n}$ & $\%$ & & \\
\hline Metabolic syndrome $(n=26)$ & 7 & 27 & 7 & 27 & 12 & 46 & & $0.73^{\star *}$ \\
\hline Moderate cardiovascular risk $(n=40)$ & 11 & 27.5 & 9 & 22.5 & 20 & 50 & & $0.77^{\star *}$ \\
\hline High cardiovascular risk $(n=16)$ & 4 & 25 & 3 & 19 & 9 & 56 & & $0.52^{\star \star \star}$ \\
\hline Carotid atherosclerosis $(n=59)$ & 16 & 27 & 13 & 22 & 30 & 51 & & $0.65^{* * *}$ \\
\hline
\end{tabular}

${ }^{*}$ The $p$-value is the result of the comparison between mild versus severe AN. ${ }^{*}$ Chi-square test. ${ }^{* *}$ Fisher's exact test.

$\mathrm{AN}=$ Acanthosis nigricans.

Table 2. Study variables by gender in children and adolescents with metabolic syndrome

\begin{tabular}{|c|c|c|c|c|c|c|}
\hline \multirow[t]{2}{*}{ Component } & \multicolumn{2}{|c|}{ Males $(n=11)$} & \multicolumn{2}{|c|}{ Females $(n=15)$} & \multirow{2}{*}{$\frac{\overrightarrow{0}}{\frac{\partial}{c}}$} & \multirow[t]{2}{*}{$p^{*}$} \\
\hline & Mean \pm SD & Min-Max & Mean \pm SD & Min-Max & & \\
\hline Waist circumference $(\mathrm{cm})$ & $102 \pm 12$ & $85-124$ & $96 \pm 14$ & $64-128$ & $\stackrel{0}{ᄃ}$ & 0.28 \\
\hline Systolic BP (mmHg) & $117 \pm 15$ & $92-148$ & $103 \pm 16$ & $70-132$ & 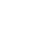 & 0.03 \\
\hline Diastolic BP (mmHg) & $69 \pm 10$ & $58-88$ & $60 \pm 10$ & $40-78$ & $\frac{5}{d}$ & 0.04 \\
\hline Triglycerides (mg/dL) & $171 \pm 42$ & $114-256$ & $152 \pm 53$ & $65-267$ & $\overline{\frac{c}{d}}$ & 0.34 \\
\hline HDL cholesterol (mg/dL) & $34 \pm 5$ & $25-40$ & $32 \pm 5$ & $19-39$ & $\frac{7}{3}$ & 0.36 \\
\hline Glucose (mg/dL) & $88 \pm 5$ & $79-94$ & $89 \pm 8$ & $76-111$ & 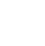 & 0.73 \\
\hline Right carotid IMT (mm) & $0.44 \pm 0.03$ & $0.40-0.51$ & $0.43 \pm 0.02$ & $0.40-0.48$ & $\frac{\varrho}{0}$ & 0.76 \\
\hline Left carotid IMT (mm) & $0.43 \pm 0.03$ & $0.40-0.52$ & $0.44 \pm 0.03$ & $0.40-0.53$ & \pm & 0.53 \\
\hline usCRP (mg/L) & $4.03 \pm 2.86$ & $1.5-9.5$ & $2.85 \pm 1.59$ & $1-7.2$ & $\stackrel{0}{c}$ & 0.31 \\
\hline
\end{tabular}

\section{Results}

Age average was $11.5 \pm 3$ years (range: 4 to 17 ). AN was mild in 16 subjects (26.6\%), moderate in $13(21.6 \%)$ and severe in 31 (51.6\%). MS was diagnosed in 26 subjects $(43 \%)$, with no difference between genders: 11 males (42\%) versus 15 females $(58 \%, p=0.58)$. The frequency of MS components was: low HDL in 26 subjects (100\%), obesity in 25 (96\%), elevated triglycerides in 24 (92\%), arterial hypertension in 10 (38\%) and hyperglycemia in one $(4 \%)$.

usCRP had average levels of $3.07 \pm 2.03 \mathrm{mg} / \mathrm{L}$ (range: 1 to 9.5). All subjects had altered usCRP: $40(67 \%)$ had moderate cardiovascular risk levels and $16(27 \%)$ had high cardiovascular risk levels; 4 subjects $(6 \%)$ were eliminated for having usCRP levels > $10 \mathrm{mg} / \mathrm{L}$. Of the 56 subjects with altered usCRP, there were equal numbers by gender: $28(50 \%, p=1.0)$.

Right common carotid average IMT was $0.44 \pm 0.04 \mathrm{~mm}$ (range: 0.40 to $0.65 \mathrm{~mm}$ ), whereas left common carotid average IMT was $0.44 \pm 0.03 \mathrm{~mm}$ (range: 0.40 to $0.55 \mathrm{~mm}$ ). Abnormal carotid IMT values for age and gender were found in 59 patients (98\%). Out of them, $29(49 \%)$ were males and $30(51 \%)$ females $(p=0.45)$.

AN severity did not influence on the investigated variables (Table 1). Among the children with MS, average blood pressure figures were statistically higher in the male gender (Table 2). Elevated triglyceride and decreased HDL levels were the alterations that conferred children with AN higher possibility for developing MS (Table 3).

\section{Discussion}

The frequency of MS in Mexican children and adolescents in our study was $43 \%$, which is lower than that reported in Brazilian children with $\operatorname{AN}(67.3 \%),{ }^{20}$ but both are superior to those found in open pediatric population. For example, in Mexican-American population, MS was reported in $18.7 \%,{ }^{21}$ whereas in Mexican population, in $19.6 \%,{ }^{22}$ which are foreseeable results if we consider that in the pathogenesis of MS obesity and insulin resistance are mainly involved, ${ }^{23}$ and both these factors are present in children with AN. 
Table 3. Distribution of variables in the presence of metabolic syndrome

\begin{tabular}{|c|c|c|c|c|c|c|c|c|c|c|}
\hline \multirow[t]{2}{*}{ Component } & \multicolumn{3}{|c|}{ With MS (n = 26) } & \multicolumn{3}{|c|}{ Without MS ( $n=34)$} & \multirow[t]{2}{*}{ p } & \multirow[t]{2}{*}{ OR } & \multicolumn{2}{|c|}{$95 \% \mathrm{C}$} \\
\hline & $\mathbf{n}$ & $\%$ & $\%$ & $\mathrm{n}$ & $\%$ & $\%$ & & & $\stackrel{\infty}{\infty}$ & \\
\hline Male gender & 11 & & 42 & 19 & & 56 & 0.58 & - & $\frac{i a}{4}$ & \\
\hline Female gender & 15 & & 58 & 15 & & 44 & 0.58 & - & 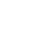 & \\
\hline Mild AN & 7 & & 27 & 9 & & 26 & 0.79 & - & है & \\
\hline Moderate AN & 7 & & 27 & 6 & & 18 & 0.36 & - & (2) & \\
\hline Severe AN & 12 & & 46 & 19 & & 56 & 0.58 & - & & \\
\hline Waist circumference $\geq 90$ & 25 & & 96 & 25 & & 74 & $0.03^{*}$ & 9 & 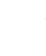 & $1-205$ \\
\hline Arterial hypertension $\geq 90$ & 10 & & 38 & 2 & & 6 & $0.001^{* *}$ & 19 & & $2-429$ \\
\hline Triglycerides $\geq 110 \mathrm{mg} / \mathrm{dL}$ & 24 & & 92 & 14 & & 41 & $0.00004^{\star *}$ & 30 & & $3-660$ \\
\hline $\mathrm{HDL}$ cholesterol $\leq 40 \mathrm{mg} / \mathrm{dL}$ & 26 & & 100 & 14 & & 41 & $0.00003^{* *}$ & $>30^{* * *}$ & 4 & \\
\hline Glucose $\geq 110 \mathrm{mg} / \mathrm{dL}$ & 1 & & 4 & 0 & & 0 & 0.42 & - & $\frac{c}{0}$ & \\
\hline Insulin resistance & 18 & & 69 & 15 & & 44 & $0.05^{\star *}$ & 3 & & $0.86-10$ \\
\hline Carotid atherosclerosis & 25 & & 96 & 34 & & 100 & $0.04^{* *}$ & 3 & & D.89-11 \\
\hline Moderate cardiovascular risk & 14 & & 54 & 26 & & 76 & 0.10 & - & $\stackrel{\Phi}{ \pm}$ & \\
\hline High cardiovascular risk & 8 & & 31 & 8 & & 24 & 0.49 & - & 3 & \\
\hline
\end{tabular}

${ }^{*}$ Two-tailed Fisher's exact test, ${ }^{* *}$ Chi-square test, ${ }^{* * *}$ Inexact. MS = Metabolic syndrome, AN = acanthosis nigricans, $\mathrm{HDL}=$ high-density lipoprotein

The importance of this MS frequency is that individuals who suffer from it in childhood have a 2.7 to 3.4 higher risk of experiencing it at adulthood, as well as twice the risk for developing carotid atherosclerosis and two to three times more risk for developing diabetes, ${ }^{24}$ in addition to a significantly higher risk of cardiovascular events, with a prevalence of $19.4 \%$, whereas in those without MS it is $1.5 \%{ }^{25}$

The most common MS components were low levels of HDL, obesity and high levels of triglycerides, with no significant difference between genders. The systolic blood pressure and diastolic blood pressure figures were statistically higher in the male gender. This last finding is similar to that reported by Halley et al., ${ }^{22}$ who observed a frequency of arterial hypertension significantly higher in male Mexicans, but not in the rest of its components.

Obesity, elevated levels of triglycerides and decreased levels of HDL are factors that increase the risk for MS in adulthood. In agreement with the Bogalusa Heart Study, obesity confers an 11-fold higher risk for the appearance of this syndrome in adulthood. ${ }^{26}$ According to the Finnish Study on Cardiovascular Risk in Young People, elevated triglycerides, low HDL cholesterol and high blood pressure figures are MS predictors. ${ }^{27}$ In our study, these components conferred higher possibility in children and adolescents with AN for the development of MS, in some cases up to 30 -fold higher risk.

As for usCRP, accumulated evidence suggests that its measurement represents a cardiovascular risk predictor that is even more powerful than LDL values, both in patients with coronary disease and in apparently healthy subjects. ${ }^{28}$ In our study all children and adolescents with AN showed usCRP levels considered of moderate or high risk. We did not observe any difference in usCRP levels between children with and without MS, but in a study that included Spanish children, the authors observed that those with obesity and MS had higher usCRP figures than those with obesity without MS, and thus the test is considered useful for cardiovascular risk factors early detection in this age group. ${ }^{29}$

Regarding atherosclerosis, the process starts since childhood, long before clinically identifiable signs and symptoms occur. In autopsies carried out in young subjects, atherosclerosis at early stages was shown to be related to obesity, triglycerides elevated levels and decreased HDL cholesterol levels. ${ }^{30}$ These metabolic alterations were present in the children and adolescents included in our study, which might explain that the fact that $98 \%$ had subclinical carotid atherosclerosis. We did not find analyses evaluating carotid IMT in children with AN, but its determination is important because it is a predictor of cardiovascular and 
stroke risk, and due to its positive correlation with both classic and emerging risk factors. . $3,30-32^{2}$

These alterations in Mexican children and adolescents with AN have an impact on economy, since in Mexico premature death associated with overweight and obesity in 2008 involved a loss of productivity of US\$ 1931 million. ${ }^{33}$ Therefore, implementation of effective actions for prevention during childhood should be a priority of health systems, since prevention programs might avoid between 47000 and 55000 deaths from chronic diseases per year. ${ }^{34}$

Although longitudinal studies with larger number of patients are required to corroborate the results, systematic exploration of children and adolescents looking for AN might help timely detection of metabolic and cardiovascular alterations, which would enable the implementation of measures to prevent morbidity and mortality in adulthood.

\section{References}

1. Nguyen TT, Keil MF, Russell DL, Pathomvanich A, Uwaifo GI, Sebring NG, et al. Relation of acanthosis nigricans to hyperinsulinemia and insulin sensitivity in overweight African American and white children. J Pediatr. 2001;138:474-480.

2. Juárez-López $C$, Klünder-Klünder $M$, Medina-Bravo $P$, Madrigal-Azcárate $A$ Mass-Díaz E, Flores-Huerta S. Insulin resistance and its association with the components of the metabolic syndrome among obese children and adolescents. BMC Public Health. 2010;10:318.

3. Sinha S, Schwartz RA. Juvenile acanthosis nigricans. J Am Acad Dermatol. 2007;57:502-508.

4. Stoddart ML, Blevins KS, Lee ET, Wang W, Blackett PR, Cherokee Diabetes Study. Association of acanthosis nigricans with hyperinsulinemia compared with other selected risk factors for type 2 diabetes in Cherokee Indians: the Cherokee Diabetes Study. Diabetes Care. 2002;25:10091014.

5. Razani B, Chakravarthy MV, Semenkovich CF. Insulin resistance and atherosclerosis. Endocrinol Metab Clin North Am. 2008;37:603-621.

6. Organisation for Economic Co-operation and Development. [Sitio web] Obesity Update 2014. [Consultado 2017 Jul 25]. Disponible en: http:// www.oecd.org/els/health-systems/Obesity-Update-2014.pdf

7. Pearson TA, Mensah GA, Alexander RW, Anderson JL, Cannon RO Criqui $\mathrm{M}$, et al. Markers of inflammation and cardiovascular disease: application to clinical and public health practice. A statement for health care professionals from the Centers for Disease Control and Prevention and the American Heart Association. Circulation. 2003;107:499-511.

8. Burke JP, Hale DE, Hazuda HP, Stern MP. A quantitative scale of acanthosis nigricans. Diabetes Care. 1999;22:1655-1659.

9. Cook S, Weitzman M, Auinger P, Nguyen M, Dietz WH. Prevalence of a metabolic syndrome phenotype in adolescents: findings from the third National Health and Nutrition Examination Survey, 1988-1994. Arch Pediatr Adolesc Med. 2003;157:821-827.

10. Fernández JR, Reeden DT, Petrobielli A, Allison DB. Waist circumference percentiles in nationally representative sample of African-American, European-American and Mexican-American children and adolescent. J Pediatr. 2004;145:439-444

11. National High Blood Pressure Education Program Working Group on High Blood Pressure in Children and Adolescents. The fourth report on the diagnosis, evaluation, and treatment of high blood pressure in children and adolescents. Pediatrics. 2004;114:555-576.

12. Amato M, Montorsi $P$, Ravani $A$, Oldani $E$, Galli $S$, Ravagnani $P M$, et al Carotid intima-media thickness by B-mode ultrasound as surrogate of coronary atherosclerosis: correlation with quantitative coronary angiography and coronary intravascular ultrasound findings. Eur Heart J. 2007;28:2094-2101.
13. Pignoli $\mathrm{P}$, Tremoli $\mathrm{E}$, Poli A, Oreste $\mathrm{P}$, Paoletti R. Intimal plus medial thickness of the arterial wall: a direct measurement with ultrasound imaging. Circulation. 1986;74:1399-1406.

14. Salonen R, Salonen JT. Determinants of carotid intima-media thickness: a population-based ultrasonography study in eastern Finnish men. $\mathrm{J}$ Intern Med. 1991;229:225-231.

15. Salonen JT, Salonen R. Ultrasound B-mode imaging in observational studies of atherosclerotic progression. Circulation. 1993;87:1156-1165.

16. Doyon A, Kracht D, Bayazit AK, Deveci M, Duzova A, Krmar RT, et al. Carotid artery intima-media thickness and distensibility in children and dolescents: reference values and role of body dimensions. Hypertension. 2013;62:550-556

17. Wang TJ, Gona P, Larson MG, Tofler GH, Levy D, Newton-Cheh C, et al Multiple biomarkers for the prediction of first major cardiovascular events and death. N Engl J Med. 2006;355:2631-2639.

18. Asher J, Houston M. Statins and C-reactive protein levels. J Clin Hypertens (Greenwich). 2007:9:622-628.

19. DeBoer MD, Gurka MJ, Sumner AE. Diagnosis of the metabolic syndrome is associated with disproportionately high levels of high-sensitivity C-reactive protein in Non-Hispanic black adolescents: an analysis of NHANES 1999-2008. Diabetes Care. 2011;34:734-740.

20. Kluczynik CE, Mariz LS, Souza LC, Solano GB, Albuquerque FC, Medeiros CC. Acanthosis nigricans and insulin resistance in overweight children and adolescents. An Bras Dermatol. 2012;87:531-537.

21. Fowler SP, Puppala S, Arya R, Chittoor G, Farook VS, Schneider J, et al. Genetic epidemiology of cardiometabolic risk factors and their clustering patterns in Mexican American children and adolescents: the SAFARI Study. Hum Genet. 2013;132:1059-1071.

22. Halley-Castillo E, Borges G, Talavera JO, Orozco R, Vargas-Alemán C, Huitrón-Bravo G, et al. Body mass index and the prevalence of metabolic syndrome among children and adolescents in two Mexican populations. J Adolesc Health. 2007;40:521-526.

23. García-García E, De-La-Llata-Romero M, Kaufer-Horwitz M, Tusié-Luna MT, Calzada-León R, Vázquez-Velázquez V, et al. La obesidad y el síndrome metabólico como problema de salud pública. Una reflexión. Salud Publica Mex. 2008:50:530-547.

24. Magnussen CG, Koskinen J, Chen W, Thomson R, Schmidt MD, Srinivasan SR, et al. Pediatric metabolic syndrome predicts adulthood metabolic syndrome, subclinical atherosclerosis, and type 2 diabetes mellitus but is no better than body mass index alone: the Bogalusa Heart Study and the Cardiovascular Risk in Young Finns Study. Circulation. 2010; 122:1604-1611.

25. Morrison JA, Friedman LA, Gray-McGuire C. Metabolic syndrome in childhood predicts adult cardiovascular disease 25 years later: the Princeton Lipid Research Clinics Follow-up Study. Pediatrics. 2007:120:340-345.

26. Srinivasan SR, Myers L, Berenson GS. Predictability of childhood adiposity and insulin for developing insulin resistance syndrome (syndrome $\mathrm{X}$ ) in young adulthood: the Bogalusa Heart Study. Diabetes. 2002:51:204-209.

27. Raitakari OT, Porkka KV, Rönnemaa T, Knip M, Uhari M, Akerblom HK, et al. The role of insulin in clustering of serum lipids and blood pressure in children and adolescents. Diabetologia 1995:38:1042-1050.

28. Arroyo-Espliguero R, Avanzas P, Kaski JC. Enfermedad cardiovascular ateroesclerótica: la utilidad de la proteína $C$ reactiva en la identificación de la placa vulnerable y del paciente "vulnerable". Rev Esp Cardiol. 2004:57:375-378.

29. Soriano-Guillén L, Hernández-García B, Pita J, Domínguez-Garrido N, Del-Río-Camacho G, Rovira A. High-sensitivity C-reactive protein is a good marker of cardiovascular risk in obese children and adolescents. Eur J Endocrinol. 2008;159:1-4

30. Berenson GS, Srinivasan SR, Bao W, Newman HP, Tracy RE, Wattigney WA. Association between multiple cardiovascular risk factors and atherosclerosis in children and young adults. The Bogalusa Heart Study. N Engl J Med. 1998:338:1650-1656.

31. McGill HC, McMahan CA, Herderick EE, Zieske AW, Malcom GT, Tracy RE, et al. Obesity accelerates the progression of coronary atherosclerosis in young men. Circulation. 2002:105:2712-2718.

32. Bots ML, Evans GW, Riley WA, Grobbee DE. Carotid intima-media thickness measurements in intervention studies: design options, progression rates, and sample size considerations: a point of view. Stroke. 2003:34:2985-2994.

33. Rtveladze K, Marsh T, Barquera S, Sanchez-Romero LM, Levy D, Melendez G, et al. Obesity prevalence in Mexico: impact on health an economic burden. Public Health Nutr. 2014;17:233-239.

34. Obesity and the economics of prevention: Fit not fat. Key facts-Mexico, update 2014. France: Organization for Economic Cooperation and Development; 2014. 